\title{
CORONAVIRUS
}

\section{IgA dominates the early neutralizing antibody response to SARS-CoV-2}

\author{
Delphine Sterlin ${ }^{1,2,3} \uparrow$, Alexis Mathian ${ }^{1,4}+$, Makoto Miyara ${ }^{1,2}+$, Audrey Mohr ${ }^{1}+$, François Anna ${ }^{5,6}+$, Laetitia Claër ${ }^{1}$, \\ Paul Quentric ${ }^{1}$, Jehane Fadlallah ${ }^{1,4}$, Hervé Devilliers ${ }^{7}$, Pascale Ghillani ${ }^{2}$, Cary Gunn ${ }^{8}$, Rick Hockett ${ }^{8}$, Sasi \\ Mudumba $^{8}$, Amélie Guihot ${ }^{1,2}$, Charles-Edouard Luyt ${ }^{9,10}$, Julien Mayaux ${ }^{11}$, Alexandra Beurton ${ }^{11,12}$, Salma \\ Fourati $^{13,14}$, Timothée Bruel ${ }^{15,16,17}$, Olivier Schwartz ${ }^{15,16,17}$, Jean-Marc Lacorte ${ }^{10,13}$, Hans Yssel ${ }^{1}$, Christophe \\ Parizot $^{1,2}$, Karim Dorgham ${ }^{1}$, Pierre Charneau ${ }^{5,6}$, Zahir Amoura $^{1,4} *$, Guy Gorochov ${ }^{1,2}$ **
}

${ }^{1}$ Sorbonne Université, Inserm, Centre d'Immunologie et des Maladies Infectieuses (CIMI-Paris), 91 boulevard de l'Hôpital, 75013 Paris, France. ${ }^{2}$ Département d'Immunologie, Assistance Publique Hôpitaux de Paris (AP-HP), 83 boulevard de l'Hôpital, Hôpital Pitié-Salpêtrière, 75013 Paris, France. ${ }^{3} U n i t$ of Antibodies in Therapy and Pathology, Institut Pasteur, UMR1222 Inserm, 25-28 Rue du Dr Roux, 75015 Paris, France. ${ }^{4}$ Service de Médecine Interne 2, Institut E3M, Assistance Publique Hôpitaux de Paris (AP-HP), Hôpital Pitié-Salpêtrière, 83 boulevard de l'Hôpital, 75013 Paris, France. 5 Unité de Virologie Moléculaire et Vaccinologie, Institut Pasteur, $25-28$ Rue du Dr Roux, 75015 Paris, France. ${ }^{T}$ Theravectys, Institut Pasteur, 25-28 Rue du Dr Roux, 75015 Paris, France. ${ }^{7}$ Centre Hospitalier Universitaire de Dijon, Hôpital FrançoisMitterrand, service de médecine interne et maladies systémiques (médecine interne 2) et Centre d'Investigation Clinique, Inserm CIC-EC 1432, 3 rue du FBG Raines 21000 Dijon, France. ${ }^{8}$ Genalyte Inc., 10520 Wareridge Circle, San Diego, CA 92121, United States of America. ${ }^{9}$ Service de Médecine Intensive Réanimation, Institut de Cardiologie, Assistance Publique-Hôpitaux de Paris (APHP), Sorbonne-Université, Hôpital Pitié-Salpêtrière, 83 boulevard de l'Hôpital, Paris 75013, France. ${ }^{10}$ Sorbonne Université, INSERM, UMRS_1166-ICAN Institute of Cardiometabolism and Nutrition, 91 boulevard de I'Hôpital, Paris 75013, France. "'Service de Médecine Intensive-Réanimation et Pneumologie, APHP Hôpital Pitié-Salpêtrière, 83 boulevard de l'Hôpital, Paris 75013, France. ${ }^{12}$ Sorbonne Université, Inserm UMRS Neurophysiologie respiratoire expérimentale et clinique, Assistance Publique Hôpitaux de Paris (AP-HP), 91 boulevard de l'Hôpital, 75013 Paris, France. ${ }^{13}$ Service de Biochimie Endocrinienne et Oncologique, Assistance Publique Hôpitaux de Paris (AP-HP), Hôpital Pitié-Salpêtrière, 83 boulevard de l'Hôpital, 75013 Paris, France. ${ }^{14}$ Inserm UMR1149, Centre de Recherche sur I'Inflammation Paris Montmartre (CRI), 16 rue Henri Huchard 75890 Paris, France. ${ }^{15}$ Virus and Immunity Unit, Department of Virology, Institut Pasteur, 25-28 Rue du Dr Roux, 75015 Paris, France. ${ }^{16}$ CNRS-UMR3569, Institut Pasteur, 25-28 Rue du Dr Roux, 75015 Paris, France. ${ }^{17}$ Vaccine Research Institute, 51 avenue du Maréchal de Lattre de Tassigny, 94000 Créteil, France.

†These authors contributed equally to this work.

$\ddagger$ These authors jointly directed this work.

*To whom correspondence should be addressed: guy.gorochov@sorbonne-universite.fr

Humoral immune responses are typically characterized by primary IgM antibody responses followed by secondary antibody responses associated with immune memory and comprised of of IgG, IgA and IgE. Here we measured acute humoral responses to SARS-CoV-2, including the frequency of antibody-secreting cells and the presence of SARS-CoV-2-specific neutralizing antibodies in the serum, saliva and broncho-alveolar fluid of 159 patients with COVID-19. Early SARS-CoV-2-specific humoral responses were dominated by IgA antibodies. Peripheral expansion of IgA plasmablasts with mucosal-homing potential was detected shortly after the onset of symptoms and peaked during the third week of the disease. The virus-specific antibody responses included IgG, IgM and IgA, but IgA contributed to virus neutralization to a greater extent compared with IgG. Specific IgA serum concentrations decreased notably one month after the onset of symptoms, but neutralizing IgA remained detectable in saliva for a longer time (days 49 to 73 post symptoms). These results represent a critical observation given the emerging information as to the types of antibodies associated with optimal protection against re-infection, and whether vaccine regimens should consider targeting a potent but potentially short-lived IgA response.

\section{INTRODUCTION}

In December 2019, a novel coronavirus named SARS-CoV2 (Severe Acute Respiratory Syndrome Coronavirus 2) was identified as the cause of an acute respiratory disease known as coronavirus disease 19 (COVID-19). This enveloped positive-sense RNA virus is a member of the betacoronavirus and spread worldwide with an unprecedented speed compared with the dissemination of SARS-CoV in 2003 and Middle East respiratory syndrome-related coronavirus virus (MERS-CoV) in 2012 (1). Recent reports indicate that SARS-CoV-2 elicits robust humoral immune responses, including production of virus-specific antibodies of the IgM, IgG, and IgA isotypes. Patients have been shown to achieve seroconversion and produce detectable antibodies within 20 days of symptom onset, although the kinetics of IgM and IgG production are variable $(2-4)$. 
Secretory IgA plays a crucial role in protecting mucosal surfaces against pathogens by neutralizing respiratory viruses or impeding their attachment to epithelial cells (5-8). Influenza-specific IgA has been shown to be more effective in preventing infections in mice and humans compared with influenza-specific IgG, and elevated IgA serum levels have been correlated with influenza vaccine efficacy (9-11). IgA may also play an important role in SARS-CoV infection. In mice, intranasal vaccination with SARS-CoV proteins induces localized and systemic virus-specific IgA responses and provides better protection against SARS-CoV challenge compared with intramuscular delivery, suggesting that mucosal-induced IgA is protective (12). A recently reported intervention based on an intranasal immunization with a MERS-derived vaccine confirmed a beneficial role of IgA (13). However, the role of virus-specific IgA against natural SARS-CoV-2 infection in humans remains poorly understood.

We tracked antibody-secreting cells, characterized here as plasmablasts, in the blood of SARS-CoV-2-infected patients. We measured specific antibody titers longitudinally in serum and compared the neutralizing capacities of purified serum monomeric IgA and IgG. Finally, we studied the neutralization potential of mucosal antibodies present in lower respiratory tract pulmonary secretions and saliva. Our results show that human IgA antibodies are often detectable before the appearance of SARS-CoV-2-specific IgG and suggest a role for IgA antibodies in early virus neutralization.

\section{RESULTS}

\section{Circulating plasmablasts preferentially express IgA1}

The rapid and transient appearance of plasmablasts in peripheral blood is a common feature of the acute phase of viral infections (14). We monitored phenotypic changes of B cells longitudinally in the blood of 38 SARS-CoV-2-infected patients (Table S1) using flow cytometry. Plasmablasts are immature antibody-secreting cells, defined here as proliferating cell cycling Ki67 ${ }^{+} \mathrm{CD} 19^{\text {low }} \mathrm{CD} 27^{\text {high }} \mathrm{CD} 38^{\text {high }}$ cells (Fig. 1A-S1A). The proportion of plasmablasts in the B cell compartment increased significantly at days 1 to 9 after the onset of symptoms (median[min-max]\%; 4.9[1.1-17.8]\% vs $0.5[0.1-1.5] \%$; $\mathrm{p}=0.0068$ ) in healthy donors; $\mathrm{n}=21$ and $\mathrm{n}=9$, respectively; Fig. $1 \mathrm{~B})$, peaked between days 10 to $15(11.8[0.7-62.1] \%, \mathrm{n}=28$, Fig. $1 B)$ and then decreased (4.4[0.2-33.8]\% between day 16 to 25 , $\mathrm{n}=21 ; 0.5[0.1-3.2] \%$, after day $50, \mathrm{n}=14$; Fig. 1B). Longitudinal follow-up in 7 patients also confirmed the transient nature of plasmablasts expansion during acute viral infection (Figure S1B).

We analyzed circulating plasmablasts for surface expression of CCR10, a chemokine receptor involved in the migration of immune cells to mucosal sites, especially the lung (15, 16). Less than $10 \%$ of memory and naive $B$ cells, but approximately $40 \%$ of detected plasmablasts, were $\mathrm{CCR}^{+} 0^{+}(3.8[1.2-$
9.6]\% in naive B cells $v s$ 10.9[4.1-47.7]\% in memory B cells $v s$ $34.9[20.7-83.4] \%$ in plasmablasts; $n=25$; Fig. $1 C$ ), suggesting a potential lung tissue tropism of the latter. Analysis of the early phase of the immune response revealed only a minor population of plasmablasts that produced IgM, as measured by intracellular staining (10.5[4.2-54.1]\% IgM $^{+}$plasmablasts; $\mathrm{n}=17$; Fig. 1D). In contrast, most plasmablasts expressed IgA (61.4[18.1-87.6]\% IgA $\mathrm{Ig}^{+}$plasmablasts vs 27.9[7.4-64.8]\% $\mathrm{IgG}^{+}$ plasmablasts; $n=17$; Fig. 1D), a feature consistent with plasmablasts that are found at mucosal sites. Intracellular IgA subclass identification showed higher frequencies of IgA1-expressing plasmablasts, as compared with IgA2 (66[26.888.5]\% IgA1 $^{+}$vs $31.6[3.7-70.8] \%$ IgA2 $^{+}$in IgA $^{+}$plasmablasts; $\mathrm{n}=13$; Figure S1C-D). This first wave of circulating IgA-expressing plasmablasts peaking between day 10 and day 15 , was followed by a second wave of IgG-expressing cells that were more dominant by day 22 after the onset of symptoms (Fig. 1E, S1E-F). The majority of IgA ${ }^{+}$plasmablasts expressed CCR10, but this chemokine receptor was expressed by a minority of $\mathrm{IgG}^{+}$plasmablasts $(60.5[37.6-92.6] \%$ vs $23.3[3.2-$ $78] \%$ CCR10+, $\mathrm{n}=15$; Figure S1G), suggesting that the latter may occupy a different niche, such as the bone marrow. Of note, the frequency of peripheral IgM-expressing plasmablasts did not vary significantly at early time points (Figure $\mathrm{S} 1 \mathrm{H}$ ) and only marginally at later time points (Figure S1I).

In a recent study that characterized the immune response of a COVID-19 patient, the induction of $\mathrm{T}$ follicular helper (Tfh) cells was reported to occur concomitantly with that of plasmablasts (17). In order to evaluate a potential germinal center origin of the plasmablast wave observed in our patients, we tracked CD4 ${ }^{+} \mathrm{CXCR}^{+} \mathrm{PD1}^{+/-} \mathrm{Tfh}$ cells longitudinally in their blood. We found no significant increase in the frequency of Tfh subsets in COVID-19 patients, as compared to healthy donors, at any of the analyzed time points (Figure S2A-B). The frequency of neither activated $\left(\mathrm{CD}^{+}{ }^{+} \mathrm{CXCR}^{+} \mathrm{PD1}^{+}\right)$, nor latent $\left(\mathrm{CD} 4^{+} \mathrm{CXCR5}^{+} \mathrm{PD1} 1^{-}\right) \mathrm{Tfh}$ cells was found to correlate with that of plasmablasts. (Figure $\mathrm{S} 2 \mathrm{C})$.

Taken together, these results point toward an early humoral response to SARS-CoV-2 dominated by IgA-expressing plasmablasts that have phenotype consistent with plasmablasts found at mucosal sites.

\section{Early SARS-CoV-2-specific IgA detection}

We assessed the prevalence of IgG, IgA and IgM antibodies recognizing the SARS-CoV-2 full-length nucleocapsid protein (NC) or spike receptor-binding domain (RBD) in serum samples from 132 infected patients (Tables S2 and S3) using a photonic ring immunoassay, which can measure the level of antibodies to multiple antigens simultaneously (Figure S3) $(18,19)$.

Data presented in Fig. 2B suggested that serum anti-RBD IgA might be detected earlier than anti-RBD IgG. In the 
subset of patients monitored at the very early time points following disease onset (first 7 days post-symptoms, $n=48$ ), antiRBD IgA and IgG were detected in 15 and 7 samples, respectively, at concentrations that did not reach statistical significance (positive samples: $31 \%$ IgA vs $15 \%$ IgG, $\mathrm{p}=0.052$; calculated from data presented in Fig. 2A-B and Figure S4A), whereas the positive rates of anti-NC were similar regardless of isotype (positive samples: 23\% IgA vs 15\% IgG, p=0.43; Fig. 2B). However, in a subset of patients monitored at multiple time points $(\mathrm{n}=38)$, time to positivity is significantly shorter for anti-RBD IgA than IgG (12[3-24] vs 15[8-24] days, $p=0.03$, Figure $\mathrm{S4B}$ ). IgM is typically considered a marker of acute infection, but anti-RBD IgM were detected only in 7 out of these 48 early samples (Fig. 2A). Moreover, anti-NC IgM remained undetectable in all samples except one. These results suggest that serum anti-RBD IgA is likely to be detected earlier than anti-RBD IgG.

The proportion of patients with detectable anti-RBD IgG increased until hitting a plateau around the fourth week postsymptom onset (positive samples: $15 \%$ day 1-7; 42\% day 8-14; $74 \%$ day $15-21$; $90 \%$ day $22-28$ and $92 \%$ day $>28$; Fig. $2 \mathrm{~A}-\mathrm{B})$. In contrast, the frequency of patients with anti-RBD IgA peaked around day 22 (positive samples: $31 \%$ day $1-7$; $51 \%$ day $8-14$; $72 \%$ day $15-21$ and $80 \%$ day 22-28; Fig. 2A-B), then decreased by day 28 (positive samples: $23 \%$ day $>28$; Fig. 2A-B). Following similar kinetics with respect to the appearance of antiRBD antibodies, the proportion of patients with detectable anti-NC IgG remained stable around the fourth week postsymptom onset (positive samples: $15 \%$ day $1-7 ; 56 \%$ day $8-14$; $85 \%$ day $15-21$; $90 \%$ day $22-28$ and $89 \%$ day $>28$; Fig. 2A-B) whereas anti-NC IgA quickly disappeared and were no longer detectable in most patients one month after disease onset (positive samples: $23 \%$ day $1-7 ; 52 \%$ day $8-14 ; 67 \%$ day $15-21$; $65 \%$ day $22-28$ and $8 \%$ day $>28$; Fig. $2 \mathrm{~A}-\mathrm{B}$ ). Of note, in two patients who recovered from COVID-19, no specific antibodies were detected at day 32 and day 47 (Fig. 2A).

Both anti-RBD and anti-NC IgG titers increased over time (anti-RBD arbitrary units/mL: 3.6[0.1-102.1] day 1-7; 8.3[0.2145.2] day $8-14 ; 32.6$ [3.5-168.9] day $15-21 ; 36.5$ [1.8-200.9] day 22-28; 57.9[5.1-209.9] day>28; anti-NC arbitrary units/mL: 2.4[0.1-138.2] day 1-7; 15.2[0.1-219.8] day 8-14; 61.7[0.1-201.7] day $15-21 ; 103.5[0.1-236.2]$ day 22-28; 82.4[0.1-200.2] day>28; Fig. 2A) whereas virus-specific IgA titers increased during the first 3 weeks post-symptom onset, then dropped and were undetectable one month after recovery (anti-RBD arbitrary units/mL: 3.7[0.1-69.6] day 1-7; 5.2[0.1-166.3] day 8-14; 9.5[0.1-58.5] day 15-21; 7.3[0.2-149.9] day 22-28; 3.1[0.1-26.4] day>28; anti-NC arbitrary units: 0.1[0.1-153.7] day 1-7; 3.9[0.1158.2] day 8-14; 25.5[0.1-128.2] day 15-21; 6.9[0.1-116.6] day 22-28; 0.1[0.1-11.9] day>28; Fig. 2A).

These results suggest that anti-SARS-CoV-2 IgA testing may improve early COVID-19 diagnosis, but serum testing more than 28 days after the onset of symptoms may only reliably detect IgG antibodies.

\section{Early SARS-CoV-2-specific IgA response is not associ- ated with COVID-19 severity}

We explored the relationship between virus-specific serum Ig titers and the clinical course of patients with COVID19. We focused the analysis on early serum samples obtained no later than ten days after the onset of clinical symptoms. A composite endpoint was used to define severe COVID-19 in patients that were initially admitted to the same non-intensive care unit (ICU) internal medicine ward and included the following criteria: transfer to the ICU, use of oxygen therapy by nasal cannula above $5 \mathrm{~L} / \mathrm{min}$, high-flow nasal cannula oxygen therapy, invasive or non-invasive mechanical ventilation, severe acute confusional state, acute renal failure and death. Taken together, early virus-specific IgG, IgM and IgA titers were not dramatically different in severe patients compared with non-severe patients (Table S4).

\section{Serum IgA is a potent and early SARS-CoV-2 neutraliz- ing agent}

We sought to determine the contribution of each of the IgG and IgA isotypes to virus neutralization. We assessed the neutralizing capacity of serum antibodies using a pseudoneutralization assay. We tested the neutralization potential of serum at a dilution of $1 / 40$, which rapidly increased during the course of disease and plateaued by day 10 post-symptom onset (Fig. 3A). Pseudovirus neutralizing activity varied considerably between patients, with half maximal inhibitory concentration (IC50) values ranging from 1/169 to 1/16189 serum dilution (Fig. 3B). We compared the pseudotyped particle entry inhibition assay with a whole virus neutralization assay based on the utilization of a live SARS-CoV-2 field isolate (Figure S5A), and we found a strong correlation between results obtained using these two assays $(\mathrm{r}=0.88, \mathrm{p}<0.0001)$, which is consistent with other published findings $(20,21)$.

We then sought to define the respective contributions of the dominant antibody isotypes to virus neutralization by using purified IgA and IgG fractions from the sera of 12 patients (Figure S5B) that were tested in parallel using the pseudovirus neutralization assay (Fig. 3C, D). Strikingly, IgA preparations were more potent in their neutralization compared with paired IgG (Fig. 3C-E). We observed that serum samples with low neutralization potential (light blue curves in Fig. 3B) also had low IgA-based neutralizing activity (corresponding light blue curves in Fig. 3D), and we confirmed that serum neutralization potential was only associated with anti-RBD IgA content and not anti-RBD IgG (Fig. 3F). IgA neutralization potential correlated directly with anti-RBD IgA serum titers ( $\mathrm{r}=-0.88, \mathrm{p}<0.0001$; Figure S5C) but not with anti-NC IgA titers ( $\mathrm{r}=0.14, \mathrm{p}=0.58$; Figure $\mathrm{S} 5 \mathrm{D})$, suggesting that IgA neutralization potential is closely linked to RBD binding. IgG is approximately five times more abundant in serum than 
IgA, but as shown, purified IgA fractions had approximately seven times lower $\mathrm{IC}_{50}$ values as compared with purified IgG ([min-max]; IgA IC I0 $^{\text {[1.1-454.9] vs IgG IC }}$ [0 [11.9-982.4]; $\mathrm{n}=18$, Fig. 3E). In addition, the more efficient neutralization potential of IgA compared with IgG cannot be explained by an avidity effect, as both purified antibody preparations were monomeric (Figure S5B).

These results suggest that IgA contributes more than IgG to serum neutralization potential in the early phase of the infection. Of note, there are exceptions to this rule, such as patients $\# 2$ and \#3, who both presented with very low antiRBD IgA levels (below $11 \mathrm{AU} / \mathrm{ml}$ between day 6 and day 18) but instead mounted an early serum IgM response (Figure S5E).

\section{Mucosal IgA is a SARS-CoV-2 neutralizing agent}

These observations detail the contributions of IgA and IgG to systemic humoral immunity. However, the main SARS-CoV-2 targets are lung epithelial cells $(22,23)$, and mucosal immunity differs from systemic immunity. To assess local mucosal immunity, saliva and bronchoalveolar lavage (BAL) samples were also tested. IgG concentrations were consistently higher than IgA in the tested BAL samples, except for one patient (Figure S5F), but IgA concentrations are higher than IgG in saliva (median[min-max]; IgA 392[921200] vs IgG $[<70-130] \mu \mathrm{g} / \mathrm{ml} ; \mathrm{n}=10$; Figure S5G). Consistent with these findings, previous reports demonstrated an increased IgG:IgA ratio along the respiratory tract, as measured from the nasal compartment to the lungs $(24,25)$. In contrast to serum-purified IgA, both monomeric and dimeric IgA were observed in bronchoalveolar fluids (Figure S5H). BAL samples were harvested at various times, including sampling as early as 4 days after symptom onset, and pseudovirus neutralization activity was detected in most samples (Fig. 3G). Anti-RBD IgA were detected in most BAL samples, whereas anti-RBD IgG were above the threshold of positivity in only half of samples (Figure S5I), suggesting that IgA may contribute more than IgG to SARS-CoV-2 neutralization in the lung. Although saliva samples were collected after day 49 postsymptom onset, 8 out of the 10 samples neutralized SARSCoV-2-pseudotyped viral particles, albeit with notable interindividual variability (Fig. 3H). Pseudovirus neutralization activity directly correlated with anti-RBD IgA titers $(\mathrm{r}=-0.796$, $\mathrm{p}<0.008$; Fig. $3 \mathrm{H}$ ) but did not correlate with anti-RBD IgG titers, although anti-RBD IgG were above the threshold of detection (Fig. 3H). Anti-RBD IgA were consistently more abundant in saliva than in serum (9.5[22.5-6.2] vs 5.2[4.3-6.8]; $\mathrm{p}=0.0039$; Fig. 3I), suggesting that SARS-CoV-2-specific IgA may persist longer at mucosal sites compared with peripheral blood in hospitalized COVID-19 patients. Observations at later time points (days 189 to 230 post-symptoms) in a series of ambulatory individuals who had experienced pauci-symptomatic COVID-19 (Table S2) revealed no detectable neutralization activity in saliva (Figure S5J).

\section{DISCUSSION}

Our data highlight the potency of IgA in the early stage of COVID-19 disease at various body sites through the analysis of blood, BAL, and saliva. We show that SARS-CoV-2 neutralization is more closely correlated with IgA than IgM or IgG in the first weeks after symptom onset. Our own results do not directly imply that monomeric IgA would be inherently more neutralizing than monomeric IgG. However, published works already suggest that SARS-Cov2-specific IgA and IgG responses are indeed qualitatively different. In arecent study based on the same variable SARS-CoV-2-specific antibody domain, but expressed as IgA or IgG, Ejemel et al. showed that the IgA monomer had significantly enhanced neutralization potency over its IgG equivalent (26). It is proposed that the increased flexibility and longer hinge of IgA1, relative to IgG (27), would be more favorable to interactions between the IgA monomer and the SARS-CoV-2 spike trimer. Previous studies in influenza- and HIV-specific antibodies have reported similar observations (28).

Another possibility is that IgA may be more broadly crossreactive against various human coronaviruses (HCoVs), as suggested from the extensive analysis of memory B cells of a survivor of the 2003 SARS-CoV outbreak (29). It is also possible that the maturation of the systemic IgG response may be slightly delayed compared with the mucosal IgA response. Our results show that serum IgA, particularly anti-RBD IgA, are detected earlier compared with IgG, and the dramatic plasmablast expansion that follows SARS-CoV-2 infection is dominated by IgA-secreting cells (Fig. 1D). The time to positivity against RBD is dramatically shorter for IgA than for IgG (Figure S4B), and serum neutralization potential is associated with anti-RBD IgA isotype antibodies (Fig. 3F). We also observed a rapid decline in SARS-CoV-2-specific IgA serum levels, thereby bringing into question the long-term efficacy of this dramatic first wave response. In convalescent individuals, plasma SARS-CoV-2-specific IgA monomers were found to be two-fold less potent in neutralization assays than IgG equivalents (30). It is also possible that sustained SARS-CoV2-specific secretory IgA levels are maintained in mucosal secretions, as we detected higher SARS-CoV-2-specific IgA titers in saliva relative to paired serum samples obtained after day 49 post-symptom onset (Fig. 3I). This observation is consistent the finding that the dimeric form of IgA, which is found in the mucosa, is more potent against authentic SARSCoV-2 than both IgA and IgG monomers (30). However, neutralizing activity was not detectable at later time points (days 189 to 230 ) in the saliva of 14 individuals who had exhibited mild, ambulatory, COVID-19 (Figure S5J).

Mucosal SARS-CoV-2-neutralizating antibodies may arise from multiple origins. Monomeric plasma IgA antibodies do 
not bind to FcRn but can reach the airways through an alternative receptor-independent process called transudation, which is more likely to occur in damaged lung tissue $(31,32)$. A clonal relationship has been shown between serum and mucosal antigen-specific IgA (33). We show that monomeric IgA are present in BAL, thus it is possible that plasma IgA antibodies could exert functions in the lower intestinal track as well. Whereas IgA and IgG may reach the airways and lungs by transudation from plasma, no significant correlation was observed between BAL and serum-specific antibody titers (Figure S5H), suggesting that a part of the SARS-CoV-2 antibody response is generated locally. Re-circulating IgA-secreting plasmablasts with a mucosal-homing profile $(16,34-$ 36) were detected in high numbers in the patients we studied and are likely to seed the lung/airway interface. IgA-secreting cells can efficiently home to and reside within the mucosa (37), and IgA subclass switch recombination can take place in these tissues (38) in a T cell-independent manner (39). The lack of correlation between plasmablast and Tfh cell expansion observed in this study suggests that germinal center-independent induction of IgA is occurring (40). Of note, several recently described SARS-CoV-2 neutralizing IgG $(41,42)$ did not carry somatic mutations typically associated with affinity maturation and $\mathrm{T}$ cell help. A molecular and functional characterization of IgA monoclonal antibodies secreted by plasmablasts found in peripheral blood during the first week of symptom onset may shed light on their mutational status. The observations made in our study could provide insight into the observation that the vast majority of children develop mild symptoms or are asymptomatic upon SARS-CoV2 infection $(43,44)$, by suggesting that cross-reactive IgA, recently identified in human gut mucosa against other targets than SARS-CoV-2 $(34,45)$, may be more prevalent in children and/or could be rapidly mobilized in response to infection with SARS-CoV-2.

We confirmed that both serum, BAL and saliva antibodies have SARS-CoV-2-neutralization potential using a pseudoneutralization assay and validated with a viral neutralization assay. It remains to be confirmed whether this response is long lasting in patients who have experienced more severe disease compared with the ambulatory patients we tested in the present study. Saliva analysis, potentially based on newly developed digital ELISA-based assays, such as the single molecule array $\left(\mathrm{Simoa}^{\mathrm{TM}}\right)(46)$, may represent a convenient way to address this issue in future studies.

In several early serum samples with efficient virus neutralizing capacity, only anti-RBD IgM were detected at measureable amounts, as neither IgA nor IgG SARS-CoV-2 spike RBD-specific antibodies were above the threshold of detection (P2 day 14 and P3 day 6 post symptoms, Figure S5E). This observation suggests that IgM may provide some level of protection as well, but this sequence of detection of IgM first, followed by IgG and IgA is unusual and not likely to be prevalent. A more typical profile is exemplified by patient $\mathrm{P} 9$, with anti-RBD IgA levels peaking before the appearance of anti-RBD IgG and barely detectable IgM at any time point (Figure S5E). Because only virus-specific IgM are detected at early time points in rare cases, it remains to be determined if all isotypes should be measured during serological diagnosis.

It was recently proposed that high levels of IgA might play a detrimental role in COVID-19 patients (47). We compared early IgA levels in patients with subsequent favorable or severe outcomes. We show that early IgA levels were not significantly higher in patients that later deteriorated (Table S4). Our results therefore do not sufficiently support the hypothesis that an early IgA response might have a potential negative influence on disease progression.

Our study has several limitations. Given the time frame covered in this study, further longitudinal studies are needed to assess whether local SARS-CoV-2-specific IgA production persists for a longer time in patients recovered from severe COVID-19, than in the paucisymptomatic individuals we have been tested at late time points. In addition, it remains to be determined whether secretory antibodies may contribute to a longer-term barrier effect in the nose and lung compared with saliva.

In conclusion, our findings suggest that IgA-mediated mucosal immunity may be a critical defense mechanism against SARS-CoV-2 at the individual level that may also reduce infectivity of human secretions, and therefore viral transmission. This finding may also inform the development of vaccines that induce specific respiratory IgA responses to SARS-CoV-2.

\section{MATERIALS AND METHODS}

\section{Study design}

We performed a single-center study carried out at APHPSorbonne Universite. The target population for the main study was composed of hospitalized, adult, SARS-CoV-2infected, patients. Blood samples were obtained in a longitudinal manner from all COVID-19 patients admitted at E3M institute, Pitié-Salpêtrière hospital over a period of one month (from April $20^{\text {th }} 2020$ onwards). Healthy individuals, controlled SARS-CoV-2-negative (PCR and serology), were recruited among laboratory staff members. Samples were processed in the Department of Immunology (G. Gorochov), located on the same hospital site. Samples were analyzed in the same department, and aliquots were shipped at $4^{\circ} \mathrm{C}$ to the Pasteur Institute for Virological Studies. Serum and saliva samples were also obtained at later time points from hospital-discharged patients consulting in the Department of Internal Medicine (Z. Amoura) of the E3M Institute for planned post-COVID clinical check-ups. An ancillary study was performed in ambulatory health care workers that never 
required hospitalization but had been exposed to SARS-CoV2 , as confirmed by PCR and/or serology.

\section{Patients recruitment and samples preparation}

Fresh blood sample from 135 consecutive adult patients with COVID-19 referred to the institute E3M, Pitié-Salpêtrière Hospital, Paris were included in the study between March 22, 2020 and April 24, 2020 and compared with 20 age and sex-matched healthy donors (HDs). The diagnosis of COVID-19 was confirmed for 125 patients, by SARS-CoV-2 carriage in the nasopharyngeal swab, as measured by realtime reverse transcription-PCR analysis (real-time RT-PCR). The ten remaining patients had a negative nasopharyngeal SARS-CoV-2 real-time RT-PCR analysis but they all had clinical symptoms and a chest computed tomography (CT) scan highly evocative of COVID-19, and they all tested positive for the presence of serum anti-SARS-CoV-2 antibodies. Demographic and clinical characteristics are detailed in Tables S1S3. To define a poor course of the disease after the admission and the first serum sampling, we used a composite endpoint including transfer to intensive care unit, use of oxygen therapy by nasal cannula above $5 \mathrm{~L} /$ minute, high-flow nasal cannula oxygen therapy, invasive or non-invasive mechanical ventilation, severe acute confusional state, acute renal failure and death. Broncho-alveolar lavages (BAL) were collected from 10 COVID-19 patients hospitalized in intensive care units at Pitié-Salpêtrière Hospital, Paris and compared with 3 COVID-19-negative samples. Demographic and clinical characteristics are detailed in Tables S5. All patients gave informed consent. This study was approved by the local ethical committee of Sorbonne Université (n $\left.{ }^{\circ} 2020-C E R 2020-21\right)$. For all patients, sera were stored immediately after collection at $-80^{\circ} \mathrm{C}$. Peripheral blood mononuclear cells (PBMCs) were isolated from the blood samples of 38 patients after FicollHypaque density gradient centrifugation (Eurobio, Courtaboeuf, France) and analyzed immediately. Clinical characteristics of these patients are presented in Table S1.

Saliva samples were self-collected by aspiration using a flexible Pasteur pipette (Fisher Scientific). Roughly 1 to $3 \mathrm{ml}$ of saliva was collected into a sterile urine cup. All saliva samples were stored at $4{ }^{\circ} \mathrm{C}$ and transported to the research lab of the Department of Immunology within 5 hours of sample collection and tested within 24 hours of sample collection.

\section{$B$ cell and $T$ cell phenotyping}

Phenotyping was assessed on freshly isolated PBMCs stained with a combination of anti-human antibodies (Table S6). Intracellular staining was performed on fixed and permeabilized cells (using the FOXP3 Transcription Factor Staining Buffer kit, eBioscience). Cells were acquired on a BD FACSCanto II Flow cytometer (BD biosciences) and analyzed with FlowJo v10 software (FlowJo, LLC).

\section{Serological analysis}

SARS-CoV-2 specific IgA, IgM and IgG antibodies were measured in 214 serum samples from 132 patients with The Maverick SARS-CoV-2 Multi-Antigen Serology Panel (Genalyte Inc. USA) according to the manufacturer's instructions. The Maverick SARS-CoV-2 Multi-Antigen Serology Panel (Genalyte Inc) is designed to detect antibodies to five SARSCoV-2 antigens: nucleocapsid, Spike S1 RBD, Spike S1S2, Spike S2 and Spike S1, with in a multiplex format based on photonic ring resonance technology $(18,19)$. This automated system detects and measures with good reproducibility (Figure S3) changes in resonance when antibodies bind to their respective antigens on the chip. Combined IgG and IgM antibodies showed $91 \%$ sensitivity and $98 \%$ specificity. Briefly, 10 $\mu \mathrm{l}$ of each serum sample was added to a sample well plate array containing required diluents and buffers, and the plate and chip were loaded in the instrument for chip equilibration with the diluent buffer to measure baseline resonance. The serum sample is then charged over the chip to bind specific antibodies to antigens present on the chip. The chip is then washed to remove low affinity binders, and specific antibodies are detected with anti-IgG, -IgA or -IgM secondary antibodies. 43 sera collected before December 2019 were analyzed to calculate cut-off values. Positivity was defined as results above the $99^{\text {th }}$ percentile.

\section{Purification and quantification of IgA and IgG from se- rum}

IgA and IgG were isolated from 12 serum samples diluted in IX-PBS as previously described (45). Sera were selected after SARS-CoV-2-specific antibody evaluation. Briefly, serum samples were load onto peptide $\mathrm{M} /$ agarose or protein $\mathrm{G} /$ agarose column (Invivogen) after column equilibration. Chromatography steps were performed at a flow rate of $0.5 \mathrm{ml} / \mathrm{min}$. Next, 20 column volumes of 1X-PBS were used to wash the column. IgA and IgG were then eluted with $5 \mathrm{ml}$ of $0.1 \mathrm{M}$ glycine (pH 2-3, Sigma-Aldrich) and $\mathrm{pH}$ was immediately adjusted to 7.5 with $1 \mathrm{M}$ Tris. 1X-PBS buffer exchange was achieved using Amicon ${ }^{\circledR}$ Ultra centrifugal filters (Merck Millipore) through a $100-\mathrm{kD}$ membrane according to the manufacturer's instructions. The quantification of IgA and IgG was determining using NanoVue Plus microvolume spectrophotometers. The purity of the IgG and IgA fractions was assessed by ELISA (IgG, IgM and IgA ELISA quantitation set, Bethyl), according to the manufacturer's recommendations. Undesirable isotypes (IgM and IgA/IgG counterparts) represented less than $1 \%$ of the purified immunoglobulins. Electrophoresis was then used to detect Ig monomers and dimers. Purified Ig ( $1 \mu \mathrm{g})$ was separated using $4 \%-20 \%$ polyacrylamide gel (Mini-PROTEAN TGX Stain-Free Precast Gels; Bio-Rad) in native conditions (Laemmli 4X, Bio-Rad). Gels were incubated with Imperial ${ }^{\mathrm{TM}}$ Protein Stain (Thermoscientific) and washed 5 times with water. 


\section{Pseudovirus production and permissive cell line gener- ation}

Pseudotyped vectors were produced by triple transfection of $293 \mathrm{~T}$ cells as previously described (48). Briefly, cells were cotransfected with plasmids encoding lentiviral proteins, a luciferase Firefly reporter, and plasmid expressing a codonoptimized SARS-CoV-2 spike (S) gene. Pseudotyped vectors were harvested at day 2 post-transfection. Functional titer (TU) was determined by qPCR after transduction of a stable Human Embronic Kidney (HEK) 293T-hACE2 cell line. To generate this cell line, HEK 293T cells were transduced at a multiplicity of infection (MOI) of 20 with an integrative lentiviral vector expressing human angiotensin converting enzyme 2 (ACE2) gene under the control of the ubiquitin $\mathrm{C}$ promoter. Clones were generated by limiting dilution and selected on their permissivity to SARS-CoV-2 S-pseudotyped lentiviral vector transduction.

\section{Pseudoneutralization Assay}

Serum dilutions were mixed and co-incubated with 300 transducing units (TU) of pseudotyped vector at room temperature for $30 \mathrm{~min}$. Serum, BAL or saliva and vector were then diluted in culture medium (DMEM-glutamax (Gibco) + $10 \%$ FCS (Gibco) + penicillin/streptomycin 1\% (Gibco). This mixture was then plated on tissue culture-treated black 96well plates (Costar) with 20,000 HEK 293T-hACE2 cells per well in suspension. To prepare the suspension, cell flasks were washed with DPBS twice (Gibco) and a single-cell suspension was made in with DPBS + 0.1\% EDTA (Promega) to preserve integrity of hACE2 protein. After $48 \mathrm{~h}$, the medium was removed from each well and bioluminescence wass measured using a luciferase assay system (Promega) on an EnSpire plate reader (PerkinElmer).

\section{Neutralization Assay}

U2OS-ACE2 GFP1-10 and GFP11 cells, also referred to as S-Fuse cells (21), were mixed (1:1 ratio) and plated at $8 \times 10^{3}$ cells per well in a 96 -well flat-bottom plate ( $\mu$ Clear, \#655090) 24 hours before infection. Cells were then infected with SARS-CoV-2 (strain BetaCoV/France/IDF0372/2020) at an MOI of 0.1. At 18 hours post-infection, cells were fixed in $4 \%$ PFA for $30 \mathrm{~min}$ at room temperature, washed, and resuspended in PBS containing Hoechst 33342 (1:10000). Images were acquired on an Opera Phenix High Content Screening System (PerkinElmer) and analyzed on Harmony High-Content Imaging and Analysis Software.

\section{Immunoblotting}

BALs were concentrated (5X) using a $100-\mathrm{kD}$ membrane (Amicon ${ }^{\circledR}$ Ultra centrifugal filters; Merck Millipore). Samples were diluted with $4 \mathrm{X}$ Laemmli sample buffer (BioRad) and heated at $95^{\circ} \mathrm{C}$ for $5 \mathrm{~min}$. Proteins were separated using $4 \%$ $20 \%$ polyacrylamide gel electrophoresis (Mini-PROTEAN TGX Stain-Free Precast Gels; Bio-Rad) for $30 \mathrm{~min}$ at $200 \mathrm{~V}$ and then were transferred to nitrocellulose for Western blot analysis. Human IgA was detected with horseradish peroxidase-conjugated goat anti-human IgA used at a 1:20,000 dilution for 1 hour (Bethyl Laboratories) followed by the addition of Enhanced Chemi-Luminescence (ECL) substrate (Clarity $^{\mathrm{TM}}$ Western ECL, Bio-Rad). Chemiluminescence was visualized with a camera system (ImageQuant ${ }^{\mathrm{TM}}$ LAS4000, GE Healthcare). All incubations were in IX-PBS with 5\% nonfat milk, and wash steps used 1X-PBS with $0.1 \%$ Tween.

\section{Statistical analysis}

Variables were expressed as the median. Several nonparametric tests were used including, the Mann-Whitney U test to compare two independent groups, the Wilcoxon test to compare paired values, and the chi-square test to compare antibody positive rates. The spearman correlation test was used to measure the correlation between two variables. Statistics were corrected for multiple comparisons with Dunn's test. Significant P-values are indicated as described: ${ }^{*} \mathrm{p}<$ $0.05 ;{ }^{* *} \mathrm{p}<0.01 ;{ }^{* * *} \mathrm{p}<0.001 ;{ }^{* * * *} \mathrm{p}<0.0001$. Statistical analysis was performed using GraphPad Prism software, V6 (GraphPad, San Diego).

\section{SUPPLEMENTARY MATERIALS}

stm.sciencemag.org/cgi/content/full/scitranslmed.abd2223/DC1

Figure S1 (related to Figure 1): Intracellular antibody expression in circulating plasmablasts.

Figure S2 (related to Figure 1): Circulating follicular helper T cells in blood of SARSCoV-2 patients.

Figure S3 (related to Figure 2): Reproducibility of photonic ring immunoassay to detect anti-RBD and anti-NC antibodies

Figure S4 (related to Figure 2): Early detection of anti-RBD antibodies in serum from SARS-CoV-2 patients.

Figure S5 (related to Figure 3): Neutralizing activity of serum, BAL and saliva from SARS-CoV-2 patients.

Table S1: Demographics, baseline characteristics, treatment, and outcome of 38 patients with COVID-19 assessed for blood plasmablasts.

Table S2: Demographics and baseline characteristics of patients with COVID-19.

Table S3: Clinical characteristics, laboratory results, treatment, and outcome of patients with COVID-19.

Table S4: Virus-specific lgG, IgM, and IgA titers according to the clinical course of the disease in patients with COVID-19

Table S5: Demographics, baseline characteristics, treatment, and outcome of patients with acute respiratory distress syndrome during course of COVID-19.

Table S6: Human antibodies used for B and T cell phenotyping.

Raw data spreadsheet

\section{REFERENCES AND NOTES}

1. S. Su, G. Wong, W. Shi, J. Liu, A. C. K. Lai, J. Zhou, W. Liu, Y. Bi, G. F. Gao, Epidemiology, Genetic Recombination, and Pathogenesis of Coronaviruses. Trends Microbiol. 24, 490-502 (2016). doi:10.1016/i.tim.2016.03.003 Medline

2. Q.-X. Long, B.-Z. Liu, H.-J. Deng, G.-C. Wu, K. Deng, Y.-K. Chen, P. Liao, J.-F. Qiu, Y. Lin, X.-F. Cai, D.-Q. Wang, Y. Hu, J.-H. Ren, N. Tang, Y.-Y. Xu, L.-H. Yu, Z. Mo, F. Gong, X.-L. Zhang, W.-G. Tian, L. Hu, X.-X. Zhang, J.-L. Xiang, H.-X. Du, H.-W. Liu, C.-H. Lang, X.-H. Luo, S.-B. Wu, X.-P. Cui, Z. Zhou, M.-M. Zhu, J. Wang, C.-J. Xue, X.-F. Li, L. Wang, Z.-J. Li, K. Wang, C.-C. Niu, Q.-J. Yang, X.-J. Tang, Y. Zhang, X.M. Liu, J.-J. Li, D.-C. Zhang, F. Zhang, P. Liu, J. Yuan, Q. Li, J.-L. Hu, J. Chen, A.-L. Huang, Antibody responses to SARS-CoV-2 in patients with COVID-19. Nat. Med. 26, 845-848 (2020). doi:10.1038/s41591-020-0897-1 Medline

3. L. Guo, L. Ren, S. Yang, M. Xiao, D. Chang, F. Yang, C. S. Dela Cruz, Y. Wang, C. Wu, Y. Xiao, L. Zhang, L. Han, S. Dang, Y. Xu, Q. W. Yang, S. Y. Xu, H. D. Zhu, Y. C. Xu, 
Q. Jin, L. Sharma, L. Wang, J. Wang, Profiling Early Humoral Response to Diagnose Novel Coronavirus Disease (COVID-19). Clin. Infect. Dis. 71, 778-785 (2020). doi:10.1093/cid/ciaa310 Medline

4. N. M. A. Okba, M. A. Müller, W. Li, C. Wang, C. H. GeurtsvanKessel, V. M. Corman, M. M. Lamers, R. S. Sikkema, E. de Bruin, F. D. Chandler, Y. Yazdanpanah, Q. Le Hingrat, D. Descamps, N. Houhou-Fidouh, C. B. E. M. Reusken, B.-J. Bosch, C. Drosten, M. P. G. Koopmans, B. L. Haagmans, Severe Acute Respiratory Syndrome Coronavirus 2-Specific Antibody Responses in Coronavirus Disease Patients. Emerg. Infect. Dis. 26, 1478-1488 (2020). doi:10.3201/eid2607.200841 Medline

5. M. B. Mazanec, C. L. Coudret, D. R. Fletcher, Intracellular neutralization of influenza virus by immunoglobulin A anti-hemagglutinin monoclonal antibodies. J. Virol. 69, 1339-1343 (1995). doi:10.1128/JVI.69.2.1339-1343.1995 Medline

6. M. B. Mazanec, C. S. Kaetzel, M. E. Lamm, D. Fletcher, J. Peterra, J. G. Nedrud, Intracellular neutralization of Sendai and influenza viruses by IgA monoclonal antibodies. Adv. Exp. Med. Biol. 371A, 651-654 (1995). doi:10.1007/978-1-46151941-6_137 Medline

7. S. Planque, M. Salas, Y. Mitsuda, M. Sienczyk, M. A. Escobar, J. P. Mooney, M.-K. Morris, Y. Nishiyama, D. Ghosh, A. Kumar, F. Gao, C. V. Hanson, S. Paul, Neutralization of genetically diverse HIV-1 strains by IgA antibodies to the gp120CD4-binding site from long-term survivors of HIV infection. AIDS 24, 875-884 (2010). doi:10.1097/0AD.0b013e3283376e88 Medline

8. C. Devito, J. Hinkula, R. Kaul, L. Lopalco, J. J. Bwayo, F. Plummer, M. Clerici, K. Broliden, Mucosal and plasma IgA from HIV-exposed seronegative individuals neutralize a primary HIV-1 isolate. AIDS 14, 1917-1920 (2000). doi:10.1097/00002030-200009080-00006 Medline

9. F. Y. Liew, S. M. Russell, G. Appleyard, C. M. Brand, J. Beale, Cross-protection in mice infected with influenza $A$ virus by the respiratory route is correlated with local IgA antibody rather than serum antibody or cytotoxic T cell reactivity. Eur. J. Immunol. 14, 350-356 (1984). doi:10.1002/eji.1830140414 Medline

10. Y. Asahi-Ozaki, T. Yoshikawa, Y. Iwakura, Y. Suzuki, S. Tamura, T. Kurata, T. Sata, Secretory IgA antibodies provide cross-protection against infection with different strains of influenza B virus. J. Med. Virol. 74, 328-335 (2004). doi:10.1002/jmv.20173 Medline

11. A. Ainai, S. Tamura, T. Suzuki, E. van Riet, R. Ito, T. Odagiri, M. Tashiro, T. Kurata, $H$. Hasegawa, Intranasal vaccination with an inactivated whole influenza virus vaccine induces strong antibody responses in serum and nasal mucus of healthy adults. Hum. Vaccin. Immunother. 9, 1962-1970 (2013). doi:10.4161/hv.25458 Medline

12. R. H. See, A. N. Zakhartchouk, M. Petric, D. J. Lawrence, C. P. Y. Mok, R. J. Hogan, T. Rowe, L. A. Zitzow, K. P. Karunakaran, M. M. Hitt, F. L. Graham, L. Prevec, J. B. Mahony, C. Sharon, T. C. Auperin, J. M. Rini, A. J. Tingle, D. W. Scheifele, D. M. Skowronski, D. M. Patrick, T. G. Voss, L. A. Babiuk, J. Gauldie, R. L. Roper, R. C. Brunham, B. B. Finlay, Comparative evaluation of two severe acute respiratory syndrome (SARS) vaccine candidates in mice challenged with SARS coronavirus. J. Gen. Virol. 87, 641-650 (2006). doi:10.1099/vir.0.81579-0 Medline

13. M. H. Kim, H. J. Kim, J. Chang, Superior immune responses induced by intranasal immunization with recombinant adenovirus-based vaccine expressing full-length Spike protein of Middle East respiratory syndrome coronavirus. PLOS ONE 14, e0220196 (2019). doi:10.1371/journal.pone.0220196 Medline

14. K. Fink, Origin and Function of Circulating Plasmablasts during Acute Viral Infections. Front. Immunol. 3, 78 (2012). doi:10.3389/fimmu.2012.00078 Medline

15. N. Xiong, Y. Fu, S. Hu, M. Xia, J. Yang, CCR10 and its ligands in regulation of epithelial immunity and diseases. Protein Cell 3, 571-580 (2012). doi:10.1007/s13238-012-2927-3 Medline

16. H. E. Mei, T. Yoshida, W. Sime, F. Hiepe, K. Thiele, R. A. Manz, A. Radbruch, T. Dörner, Blood-borne human plasma cells in steady state are derived from mucosal immune responses. Blood 113, 2461-2469 (2009). doi:10.1182/blood-2008-04$\underline{153544}$ Medline

17. I. Thevarajan, T. H. O. Nguyen, M. Koutsakos, J. Druce, L. Caly, C. E. van de Sandt, X. Jia, S. Nicholson, M. Catton, B. Cowie, S. Y. C. Tong, S. R. Lewin, K. Kedzierska, Breadth of concomitant immune responses prior to patient recovery: A case report of non-severe COVID-19. Nat. Med. 26, 453-455 (2020). doi:10.1038/s41591-020-0819-2 Medline
18. M. Miyara, J.-L. Charuel, S. Mudumba, A. Wu, P. Ghillani-Dalbin, Z. Amoura, R. W. Burlingame, L. Musset, Detection in whole blood of autoantibodies for the diagnosis of connective tissue diseases in near patient testing condition. PLOS ONE 13, e0202736 (2018). doi:10.1371/journal.pone.0202736 Medline

19. S. Mudumba, S. de Alba, R. Romero, C. Cherwien, A. Wu, J. Wang, M. A. Gleeson, M. Iqbal, R. W. Burlingame, Photonic ring resonance is a versatile platform for performing multiplex immunoassays in real time. J. Immunol. Methods 448, 3443 (2017). doi:10.1016/i.jim.2017.05.005 Medline

20. L. Grzelak, S. Temmam, C. Planchais, C. Demeret, L. Tondeur, C. Huon, F. GuivelBenhassine, I. Staropoli, M. Chazal, J. Dufloo, D. Planas, J. Buchrieser, M. M. Rajah, R. Robinot, F. Porrot, M. Albert, K.-Y. Chen, B. Crescenzo-Chaigne, F. Donati, F. Anna, P. Souque, M. Gransagne, J. Bellalou, M. Nowakowski, M. Backovic, L. Bouadma, L. Le Fevre, Q. Le Hingrat, D. Descamps, A. Pourbaix, C. Laouénan, J. Ghosn, Y. Yazdanpanah, C. Besombes, N. Jolly, S. Pellerin-Fernandes, O. Cheny, M.-N. Ungeheuer, G. Mellon, P. Morel, S. Rolland, F. A. Rey, S. Behillil, V. Enouf, A. Lemaitre, M.-A. Créach, S. Petres, N. Escriou, P. Charneau, A. Fontanet, B. Hoen, T. Bruel, M. Eloit, H. Mouquet, O. Schwartz, S. van der Werf, A comparison of four serological assays for detecting anti-SARS-CoV-2 antibodies in human serum samples from different populations. Sci. Transl. Med. 12, eabc3103 (2020). doi:10.1126/scitranslmed.abc3103 Medline

21. J. Buchrieser, J. Dufloo, M. Hubert, B. Monel, D. Planas, M. M. Rajah, C. Planchais, F. Porrot, F. Guivel-Benhassine, S. Van der Werf, N. Casartelli, H. Mouquet, T. Bruel, O. Schwartz, Syncytia formation by SARS-CoV-2-infected cells. EMBO J. •.•, e106267 (2020). Medline

22. D. H. Brann, T. Tsukahara, C. Weinreb, M. Lipovsek, K. Van den Berge, B. Gong, R. Chance, I. C. Macaulay, H. J. Chou, R. B. Fletcher, D. Das, K. Street, H. R. de Bezieux, Y.-G. Choi, D. Risso, S. Dudoit, E. Purdom, J. Mill, R. A. Hachem, H. Matsunami, D. W. Logan, B. J. Goldstein, M. S. Grubb, J. Ngai, S. R. Datta, Nonneuronal expression of SARS-CoV-2 entry genes in the olfactory system suggests mechanisms underlying COVID-19-associated anosmia. bioRxiv 6 , 2020.03.25.009084 (2020). Medline

23. L. Fodoulian, J. Tuberosa, D. Rossier, B. N. Landis, A. Carleton, I. Rodriguez, SARSCoV-2 receptor and entry genes are expressed by sustentacular cells in the human olfactory neuroepithelium. bioRxiv, 2020.03.31.013268 (2020).

24. H. Y. Reynolds, Immunoglobulin $\mathrm{G}$ and its function in the human respiratory tract. Mayo Clin. Proc. 63, 161-174 (1988). doi:10.1016/S0025-6196(12)64949-0 Medline

25. R. H. Waldman, P. F. Jurgensen, G. N. Olsen, R. Ganguly, J. E. Johnson 3rd, Immune response of the human respiratory tract. I. Immunoglobulin levels and influenza virus vaccine antibody response. J. Immunol. 111, 38-41 (1973). Medline

26. M. Ejemel, Q. Li, S. Hou, Z. A. Schiller, J. A. Tree, A. Wallace, A. Amcheslavsky, N. Kurt Yilmaz, K. R. Buttigieg, M. J. Elmore, K. Godwin, N. Coombes, J. R. Toomey, R. Schneider, A. S. Ramchetty, B. J. Close, D.-Y. Chen, H. L. Conway, M. Saeed, C. Ganesa, M. W. Carroll, L. A. Cavacini, M. S. Klempner, C. A. Schiffer, Y. Wang, A cross-reactive human IgA monoclonal antibody blocks SARS-CoV-2 spike-ACE2 interaction. Nat. Commun. 11, 4198 (2020). doi:10.1038/s41467-020-18058-8 Medline

27. M. K. Boehm, J. M. Woof, M. A. Kerr, S. J. Perkins, The Fab and Fc fragments of IgAl exhibit a different arrangement from that in IgG: A study by X-ray and neutron solution scattering and homology modelling. J. Mol. Biol. 286, 1421-1447 (1999). doi:10.1006/jmbi.1998.2556 Medline

28. M. Muramatsu, R. Yoshida, A. Yokoyama, H. Miyamoto, M. Kajihara, J. Maruyama, N. Nao, R. Manzoor, A. Takada, Comparison of antiviral activity between IgA and IgG specific to influenza virus hemagglutinin: Increased potential of IgA for heterosubtypic immunity. PLOS ONE 9, e85582 (2014). doi:10.1371/journal.pone.0085582 Medline

29. A. Z. Wec, D. Wrapp, A. S. Herbert, D. P. Maurer, D. Haslwanter, M. Sakharkar, R K. Jangra, M. E. Dieterle, A. Lilov, D. Huang, L. V. Tse, N. V. Johnson, C.-L. Hsieh, N. Wang, J. H. Nett, E. Champney, I. Burnina, M. Brown, S. Lin, M. Sinclair, C. Johnson, S. Pudi, R. Bortz 3rd, A. S. Wirchnianski, E. Laudermilch, C. Florez, J. M. Fels, C. M. O'Brien, B. S. Graham, D. Nemazee, D. R. Burton, R. S. Baric, J. E. Voss, K. Chandran, J. M. Dye, J. S. McLellan, L. M. Walker, Broad neutralization of SARSrelated viruses by human monoclonal antibodies. Science 369, 731-736 (2020). doi:10.1126/science.abc7424 Medline

30. Z. Wang, J. C. C. Lorenzi, F. Muecksch, S. Finkin, C. Viant, C. Gaebler, M. Cipolla, 
H.-H. Hoffman, T. Y. Oliveira, D. A. Oren, V. Ramos, L. Nogueira, E. Michailidis, D. F. Robbiani, A. Gazumyan, C. M. Rice, T. Hatziioannou, P. D. Bieniasz, M. Caskey, M. C. Nussenzweig, Enhanced SARS-CoV-2 Neutralization by Secretory IgA in vitro. bioRxiv 2020.09.09.288555 (2020). Medline

31. D. Burnett, Immunoglobulins in the lung. Thorax 41, 337-344 (1986). doi:10.1136/thx.41.5.337 Medline

32. R. A. Stockley, M. Mistry, A. R. Bradwell, D. Burnett, A study of plasma proteins in the sol phase of sputum from patients with chronic bronchitis. Thorax 34, 777782 (1979). doi:10.1136/thx.34.6.777 Medline

33. R. Iversen, O. Snir, M. Stensland, J. E. Kroll, Ø. Steinsbø, I. R. Korponay-Szabó, K. E. A. Lundin, G. A. de Souza, L. M. Sollid, Strong Clonal Relatedness between Serum and Gut IgA despite Different Plasma Cell Origins. Cell Rep. 20, 2357-2367 (2017). doi:10.1016/i.celrep.2017.08.036 Medline

34. J. J. Bunker, S. A. Erickson, T. M. Flynn, C. Henry, J. C. Koval, M. Meisel, B. Jabri, D. A. Antonopoulos, P. C. Wilson, A. Bendelac, Natural polyreactive IgA antibodies coat the intestinal microbiota. Science 358, eaan6619 (2017). doi:10.1126/science. aan6619 Medline

35. M. Dullaers, D. Li, Y. Xue, L. Ni, I. Gayet, R. Morita, H. Ueno, K. A. Palucka, J. Banchereau, S. Oh, A T cell-dependent mechanism for the induction of human mucosal homing immunoglobulin A-secreting plasmablasts. Immunity 30, 120129 (2009). doi:10.1016/i.immuni.2008.11.008 Medline

36. T. Nakayama, K. Hieshima, D. Izawa, Y. Tatsumi, A. Kanamaru, O. Yoshie, Cutting edge: Profile of chemokine receptor expression on human plasma cells accounts for their efficient recruitment to target tissues. J. Immunol. 170, 1136-1140 (2003). doi:10.4049/iimmunol.170.3.1136 Medline

37. J. R. Mora, M. Iwata, B. Eksteen, S.-Y. Song, T. Junt, B. Senman, K. L. Otipoby, A. Yokota, H. Takeuchi, P. Ricciardi-Castagnoli, K. Rajewsky, D. H. Adams, U. H. von Andrian, Generation of gut-homing IgA-secreting B cells by intestinal dendritic cells. Science 314, 1157-1160 (2006). doi:10.1126/science.1132742 Medline

38. M. Lin, L. Du, P. Brandtzaeg, Q. Pan-Hammarström, IgA subclass switch recombination in human mucosal and systemic immune compartments. Mucosal Immunol. 7, 511-520 (2014). doi:10.1038/mi.2013.68 Medline

39. B. He, W. Xu, P. A. Santini, A. D. Polydorides, A. Chiu, J. Estrella, M. Shan, A. Chadburn, V. Villanacci, A. Plebani, D. M. Knowles, M. Rescigno, A. Cerutti, Intestinal bacteria trigger $T$ cell-independent immunoglobulin $A(2)$ class switching by inducing epithelial-cell secretion of the cytokine APRIL. Immunity 26 , 812-826 (2007). doi:10.1016/i.immuni.2007.04.014 Medline

40. M. A. Berkowska, G. J. A. Driessen, V. Bikos, C. Grosserichter-Wagener, K Stamatopoulos, A. Cerutti, B. He, K. Biermann, J. F. Lange, M. van der Burg, J. J. M. van Dongen, M. C. van Zelm, Human memory B cells originate from three distinct germinal center-dependent and -independent maturation pathways. Blood 118, 2150-2158 (2011). doi:10.1182/blood-2011-04-345579 Medline

41. B. Ju, Q. Zhang, J. Ge, R. Wang, J. Sun, X. Ge, J. Yu, S. Shan, B. Zhou, S. Song, X. Tang, J. Yu, J. Lan, J. Yuan, H. Wang, J. Zhao, S. Zhang, Y. Wang, X. Shi, L. Liu, J. Zhao, X. Wang, Z. Zhang, L. Zhang, Human neutralizing antibodies elicited by SARS-CoV-2 infection. Nature 584, 115-119 (2020). doi:10.1038/s41586-0202380-z Medline

42. R. Shi, C. Shan, X. Duan, Z. Chen, P. Liu, J. Song, T. Song, X. Bi, C. Han, L. Wu, G. Gao, X. Hu, Y. Zhang, Z. Tong, W. Huang, W. J. Liu, G. Wu, B. Zhang, L. Wang, J. Qi, H. Feng, F.-S. Wang, Q. Wang, G. F. Gao, Z. Yuan, J. Yan, A human neutralizing antibody targets the receptor-binding site of SARS-CoV-2. Nature 584, 120-124 (2020). doi:10.1038/s41586-020-2381-y Medline

43. X. Lu, L. Zhang, H. Du, J. Zhang, Y. Y. Li, J. Qu, W. Zhang, Y. Wang, S. Bao, Y. Li, C. Wu, H. Liu, D. Liu, J. Shao, X. Peng, Y. Yang, Z. Liu, Y. Xiang, F. Zhang, R. M. Silva, K. E. Pinkerton, K. Shen, H. Xiao, S. Xu, G. W. K. Wong; Chinese Pediatric Novel Coronavirus Study Team, SARS-CoV-2 Infection in Children. N. Engl. J. Med. 382 , 1663-1665 (2020). doi:10.1056/NEJMc2005073 Medline

44. P. Zimmermann, N. Curtis, Coronavirus Infections in Children Including COVID-19: An Overview of the Epidemiology, Clinical Features, Diagnosis, Treatment and Prevention Options in Children. Pediatr. Infect. Dis. J. 39, 355-368 (2020). doi:10.1097/INF.0000000000002660 Medline

45. D. Sterlin, J. Fadlallah, O. Adams, C. Fieschi, C. Parizot, K. Dorgham, A. Rajkumar, G. Autaa, H. El-Kafsi, J.-L. Charuel, C. Juste, F. Jönsson, T. Candela, H. Wardemann, A. Aubry, C. Capito, H. Brisson, C. Tresallet, R. D. Cummings, M. Larsen, H. Yssel, S. von Gunten, G. Gorochov, Human IgA binds a diverse array of commensal bacteria. J. Exp. Med. 217, e20181635 (2020). doi:10.1084/jem.20181635 Medline

46. M. Norman, T. Gilboa, A. F. Ogata, A. M. Maley, L. Cohen, Y. Cai, J. Zhang, J. E. Feldman, B. M. Hauser, T. M. Caradonna, B. Chen, A. G. Schmidt, G. Alter, R. C. Charles, E. T. Ryan, D. R. Walt, Ultra-Sensitive High-Resolution Profiling of AntiSARS-CoV-2 Antibodies for Detecting Early Seroconversion in COVID-19 Patients. medRxiv 2020.04.28.20083691 (2020). Medline

47. H.-Q. Yu, B.-Q. Sun, Z.-F. Fang, J.-C. Zhao, X.-Y. Liu, Y.-M. Li, X.-Z. Sun, H.-F. Liang, B. Zhong, Z.-F. Huang, P.-Y. Zheng, L.-F. Tian, H.-Q. Qu, D.-C. Liu, E.-Y. Wang, X.J. Xiao, S.-Y. Li, F. Ye, L. Guan, D.-S. Hu, H. Hakonarson, Z.-G. Liu, N.-S. Zhong, Distinct features of SARS-CoV-2-specific IgA response in COVID-19 patients. Eur. Respir. J. 56, 2001526 (2020). doi:10.1183/13993003.01526-2020 Medline

48. M. C. Iglesias, K. Mollier, A.-S. Beignon, P. Souque, O. Adotevi, F. Lemonnier, P. Charneau, Lentiviral vectors encoding HIV-1 polyepitopes induce broad CTL responses in vivo. Mol. Ther. 15, 1203-1210 (2007). doi:10.1038/si.mt.6300135 Medline

Acknowledgments: The authors wish to thank the patients that agreed to participate in this study, as well as the doctors and nurses from the endocrinology, metabolism, nutrition and diabetology departments of Institut E3M (Assistance Publique Hôpitaux de Paris (AP-HP), Hôpital Pitié-Salpêtrière, 75013 Paris, France) who participated in this study, all members from the Immunology Department, (Assistance Publique Hôpitaux de Paris (AP-HP), Hôpital Pitié-Salpêtrière, 75013 Paris, France), who volunteered to process blood and BAL samples, and administrative staff at the Research and Innovation office of Pitié-Salpêtrière Hospital for their support, Laura Wakselman from the Clinical Research Unit (URC) of Pitié-Salpêtrière Hospital for help with regulatory and ethical compliance, Claire Fieschi for the recruitment of SARS-CoV-2-exposed health care workers, and Avidan U. Neumann for discussions and ideas. We thank Nathalie Aulner and the UtechS Photonic Biolmaging (UPBI) core facility (Institut Pasteur), a member of the France Biolmaging network, for image acquisition and analysis. Funding: D.S. was supported for this work by a Pasteur/APHP interface fellowship. The study was supported by Fondation de France, «Tous unis contre le virus » framework Alliance (Fondation de France, AP-HP, Institut Pasteur) in collaboration with Agence Nationale de la Recherche (ANR Flash COVID19 program), and by the SARS-CoV-2 Program of the Faculty of Medicine from Sorbonne University ICOViD programs, PI: G.G.). Work in UPBI is funded by grant ANR-10-INSB-04-01 and Reǵion lle-de-France program DIM1Health. Author contributions: A.Ma., J.F., A.G. C.E.L., J.M., A.B., Z.A., recruited patients. A.Ma., J.F., P.Q., A.G. C.E.L., J.M., Z.A., collected demographic and clinical data. D.S., A.Mo., L.C., P.Q., C.P., K.D., J.M.L., P.G., prepared the specimens. D.S., M.M., A.Mo., L.C., K.D. T.D. designed and performed experiments. F.A. and P.C. designed, performed and analyzed neutralization assays. D.S., A.Mo., L.C., F.A., analyzed data. D.S., A.Mo., F.A. prepared the figures. H.D. reviewed statistical analysis of clinical data. D.S. and G.G. wrote the manuscript draft. D.S., A. Ma., M.M., A. Mo., O.S., H.Y., J.M.L., Z.A., G.G. designed the study and reviewed the manuscript. Competing interests: M.M. received consulting fees from Genalyte Inc. 3 years ago. G. G. is a scientific advisor for Luxia Scientific. Other authors declare that they have no competing interests. Data and Materials Availability: All data are available in the manuscript or the supplementary materials. Serum samples are available upon reasonable request to G. Gorochov under a material transfer agreement (MTA) with Inserm. Pseudotyped vectors and S-Fuse cells are available upon request to $P$. Charneau (pierre.charneau@pasteur.fr) and 0. Schwartz (olivier.schwartz@pasteur.fr), respectively, under a material transfer agreement (MTA) with the Pasteur Institute. Reagents used for human flow cytometry are all commercially available and non-proprietary. This work is licensed under a Creative Commons Attribution 4.0 International (CC BY 4.0) license, which permits unrestricted use, distribution, and reproduction in any medium, provided the original work is properly cited. To view a copy of this license, visit https://creativecommons.org/licenses/by/4.0/. This license does not apply to figures/photos/artwork or other content included in the article that is credited to a third party; obtain authorization from the rights holder before using this material. 
Submitted 8 June 2020

Resubmitted 26 August 2020

Accepted 1 December 2020

Published First Release 7 December 2020

10.1126/scitranslmed.abd2223 

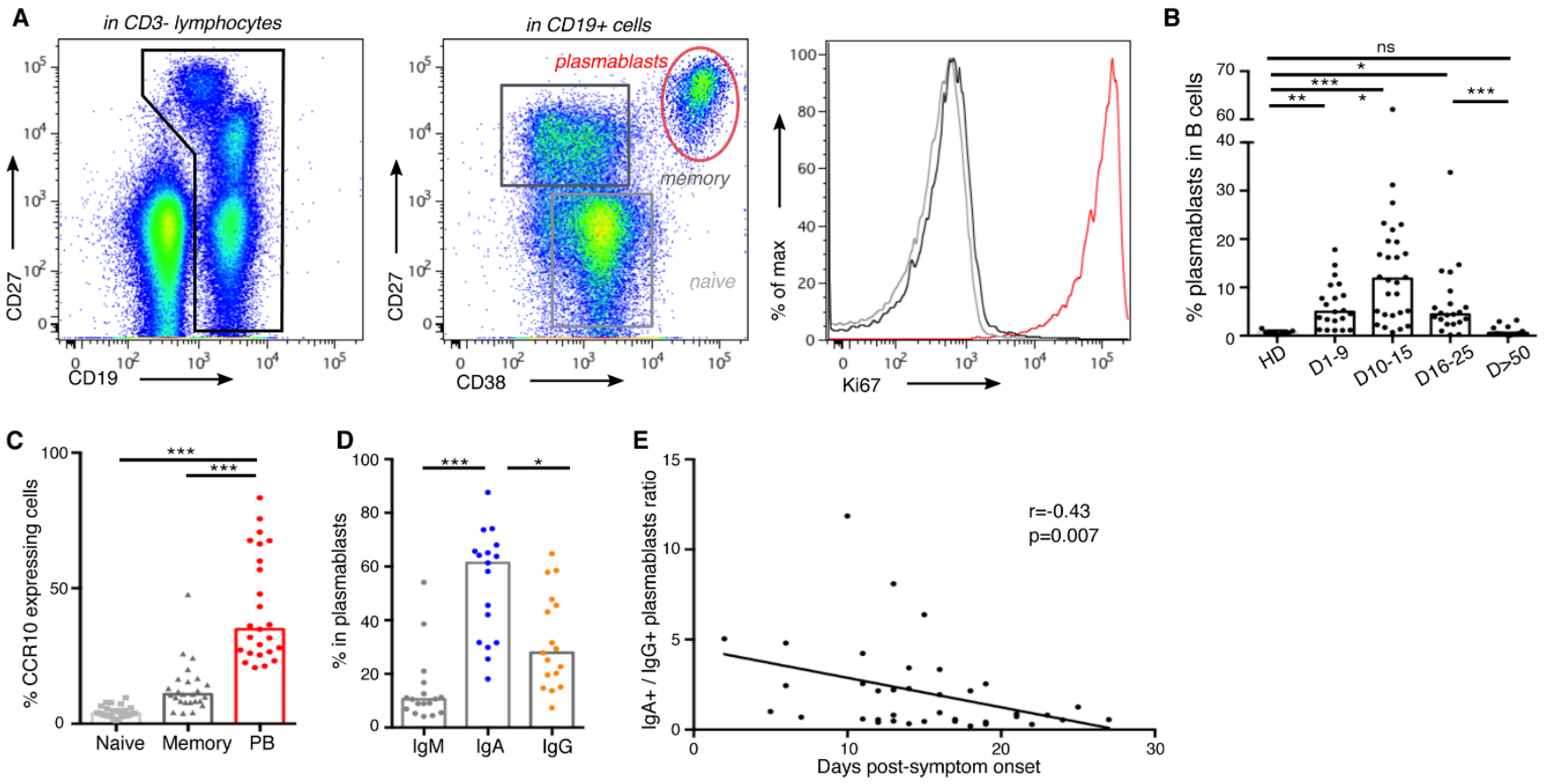

Fig. 1. Plasmablast dynamics following SARS-CoV-2 infection. A. Representative flow cytometry analysis of $B$ cell subpopulations in the blood of SARS-CoV-2 infected patients. Doublets and dead cells were excluded

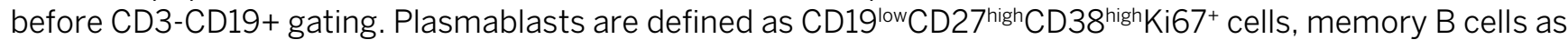

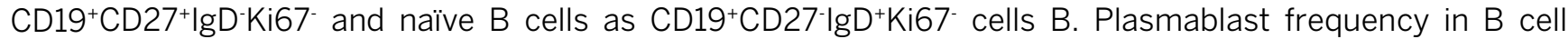
compartment in blood of SARS-CoV-2 infected patients ( $n=38$, clinical characteristics in Table S1) compared with healthy donors $(n=9)$. Histograms represent medians. P-values were calculated using Dunn's multiple comparison test $\left({ }^{*} p<0.05 ;{ }^{* *} p<0.01 ;{ }^{* *} p<0.001\right)$. C. Flow cytometry analysis of CCR10 expression in B cell subpopulations in blood of SARS-CoV-2 infected patients $(n=25)$. Samples used in this analysis were collected from day 3 to 27 after symptom onset. Histograms represent medians. P-values were calculated using Wilcoxon test $(* * * 00.001)$. D. Intracellular antibody expression in circulating plasmablasts in blood of SARSCoV-2 infected patients $(n=17)$ using flow cytometry. Samples used in this analysis were collected from day 2 to 23 after symptom onset. Histograms represent medians. P-values were calculated using Dunn's multiple comparison test ( $\left.{ }^{*} \mathrm{p}<0.05 ;{ }^{* *} \mathrm{p}<0.001\right)$. E. Intracellular IgA versus IgG expression in plasmablasts according to disease duration. Each dot represents one patient. Non-parametric Spearman correlation was calculated. 

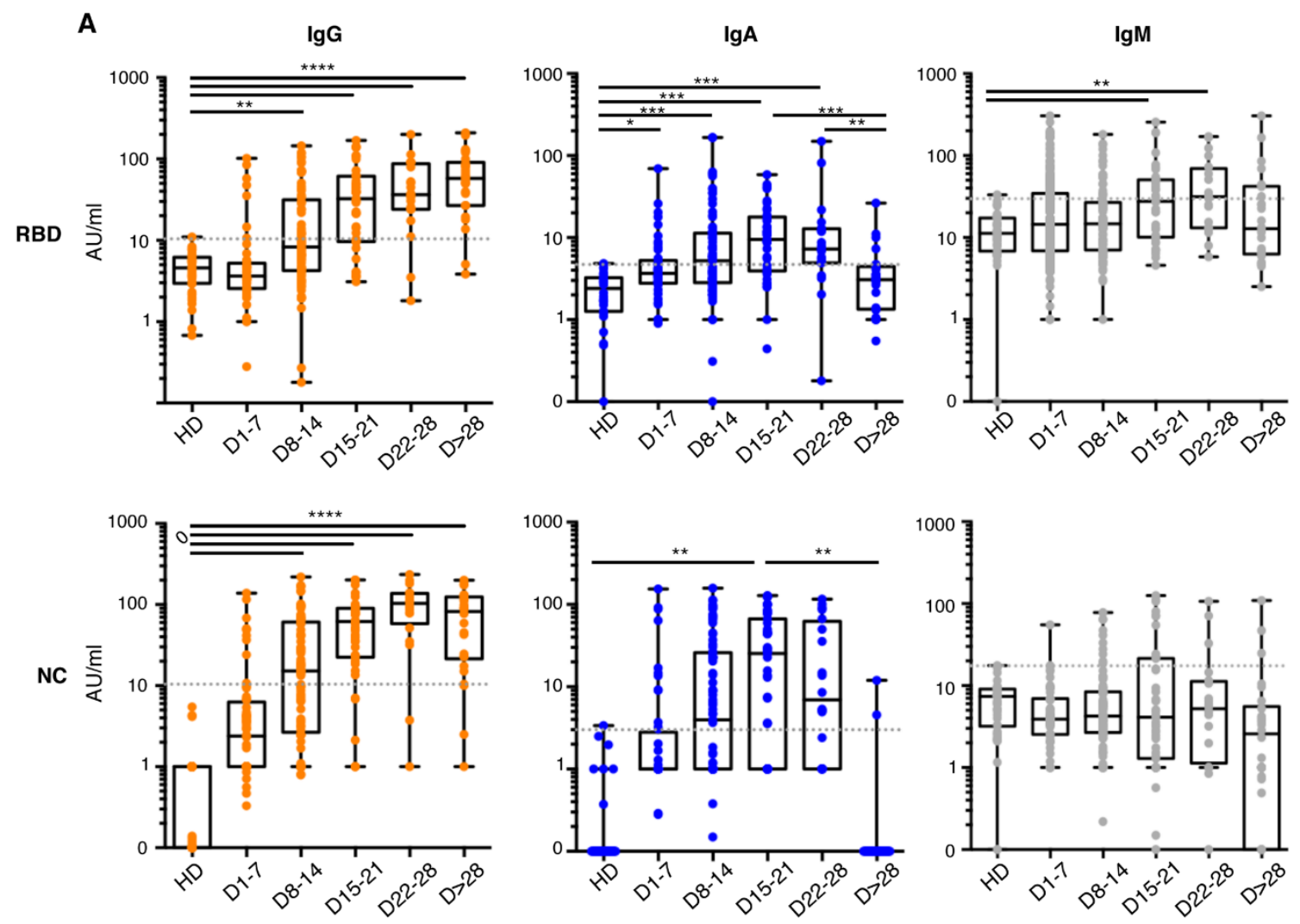

Days after symptoms onset
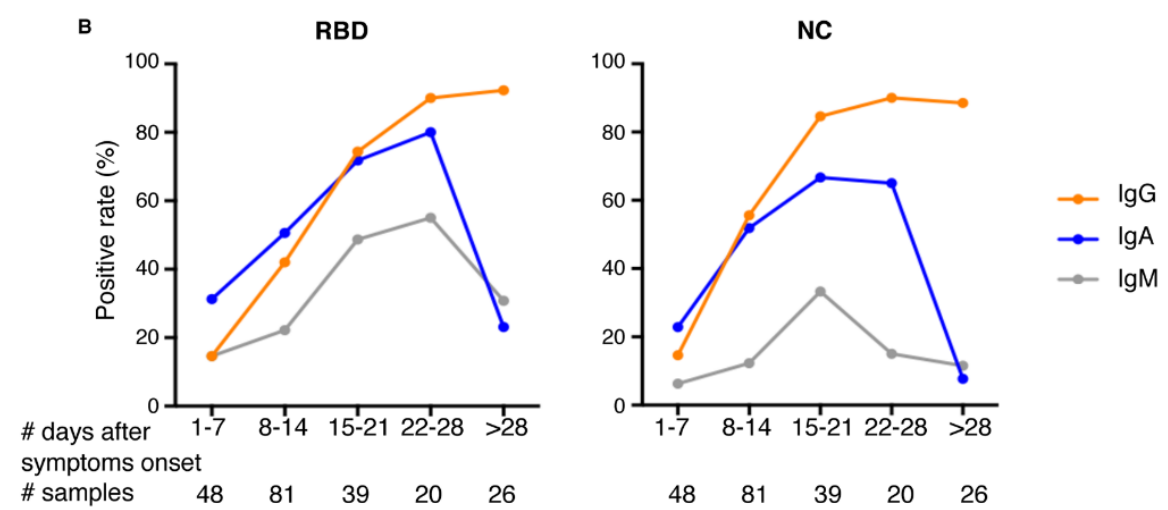

Fig. 2. Antibody responses kinetics to SARS-CoV-2 proteins. A. Specific IgG, IgA, and IgM against spike-1 receptor binding domain (RBD) and Nucleocapsid protein (NC) were measured using photonic ring immunoassay in 132 patients (clinical characteristics detailed in Tables S2-S3). Antibody levels are expressed as arbitrary units $/ \mathrm{ml}(\mathrm{AU} / \mathrm{ml})$. Cut-off lines are represented as grey dotted lines. The boxplots show medians (middle line) and first and third quartiles and the whiskers indicate minimal and maximal values. P-value was calculated using Dunn's multiple comparison test $\left({ }^{*} p<0.05\right.$; ${ }^{* *} p<0.01$ : ${ }^{* * *} p<0.001$; $* * * * p<0.0001$ ). B. Positive rates of specific serum IgG, IgA, and IgM in 132 patients at different times after symptom onset, from day 1 to 78. 

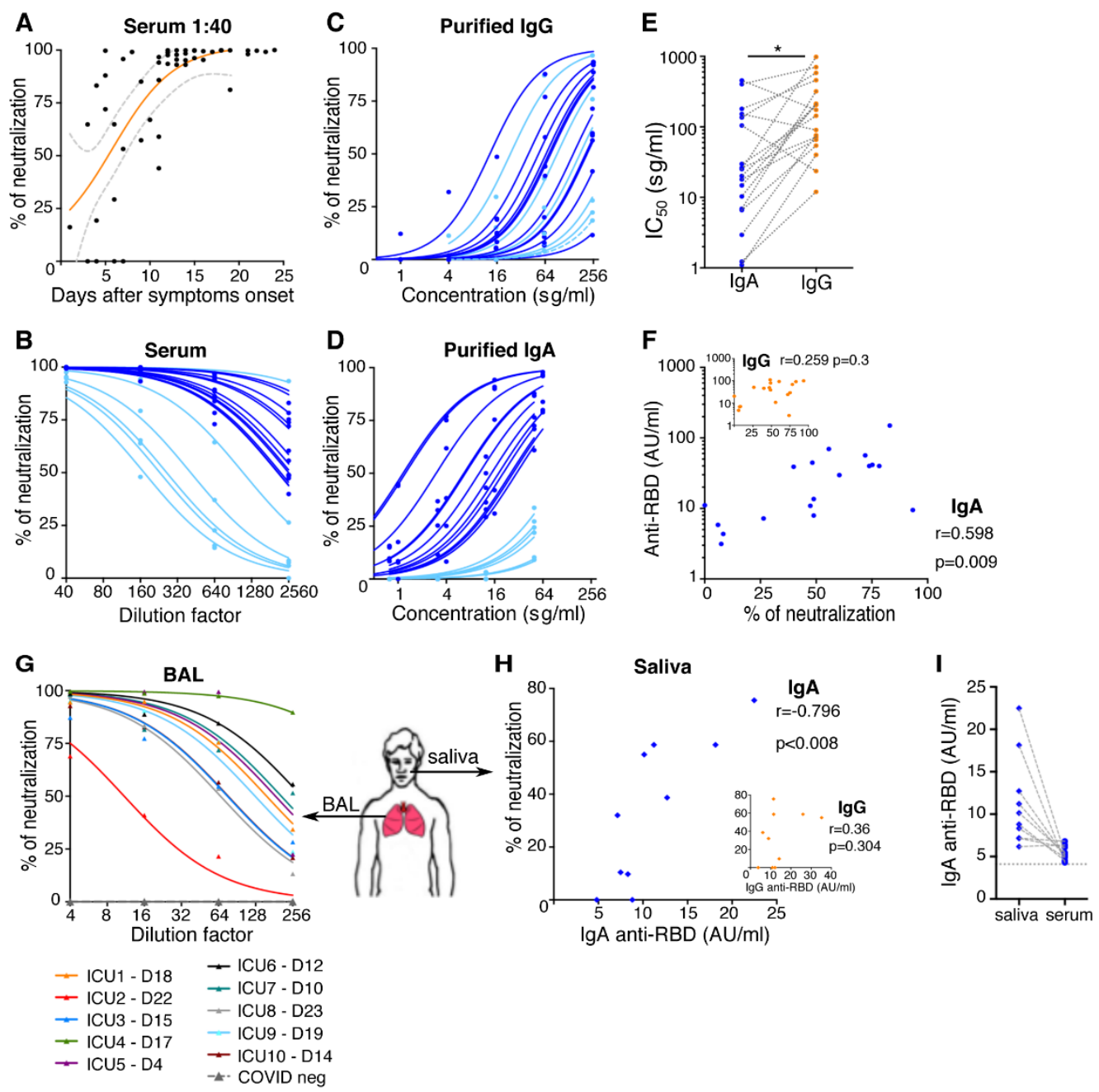

Fig. 3. Neutralizing activity of serum antibodies to SARS-CoV-2. A. Neutralizing activity of 52 sera (dilution 1:40) from 38 SARS-CoV-2 infected patients (see clinical characteristics in Table S1) was determined using a pseudovirus neutralization assay. Orange curve represents significant sigmoidal interpolation $(p=0.0082)$. Grey dotted curves represent $95 \%$ confidence intervals. B. Neutralizing activity of 18 sera measured by pseudovirus neutralization assay at different indicated dilutions. Samples used for this analysis were collected between day 6 and 24 after symptom onset. Light blue color corresponds to samples with low IgA neutralization potential. C. Neutralizing activity of purified IgG was measured at indicated concentrations from 18 sera collected between day 6 and day 24 postsymptom onset. Curves were drawn according to non-linear regression. Light blue color corresponds to samples with low IgA neutralization potential. D. Neutralizing activity of purified IgA from paired samples in Fig. 3C. Light blue color corresponds to samples with low IgA neutralization potential. E. Paired purified IgA and $\lg \mathrm{IC}_{50}$ values in samples tested in Figs. $3 C$ and D. P-value was calculated using Wilcoxon test $\left({ }^{*} p<0.05\right)$. F. Comparison of serum anti-RBD IgA (main panel) or IgG (insert) levels measured by photonic ring immunoassay with neutralizing capacity of corresponding purified isotypes measured by pseudovirus neutralization assay. Spearman coefficient $(r)$ and $P$ value (p) are indicated. G. Neutralizing activity of bronchoalveolar lavages (BAL) collected in 10 SARS-CoV-2 patients between day 4 and 23 after symptom onset (clinical characteristics are detailed in Table S5). Indicated BAL dilutions were tested using pseudovirus neutralization assay. Bronchoalveolar lavages obtained from SARS-CoV-2 negative patients $(n=3)$ showed no neutralization activity (dotted grey lines). Each colored line represents one patient. $H$. Neutralizing activity and anti-RBD IgA levels (both tested at dilution 1:4) of saliva collected in 10 SARS-CoV-2 patients between day 49 and 73 after symptom onset. Spearman coefficient ( $r$ ) and P-value (p) are indicated. I. Anti-RBD levels in paired saliva and serum from patients tested in Fig. $3 \mathrm{H}$. P-value was calculated using Wilcoxon test $\left({ }^{* *} \mathrm{p}<0.01\right)$. 